November 2012

\title{
Venoarterial extracorporeal membrane oxygenation (ECMO) for support during whole lung lavage for pulmonary alveolar proteinosis.
}

\author{
Hitoshi Hirose \\ Thomas Jefferson University \\ Julie Monteagudo \\ Thomas Jefferson University \\ Nicholas C. Cavarocchi \\ Thomas Jefferson University \\ Boyd Hehn \\ Thomas Jefferson University \\ Naveed Hasan \\ Thomas Jefferson University \\ Follow this and additional works at: https://jdc.jefferson.edu/surgeryfp \\ Part of the Surgery Commons \\ Let us know how access to this document benefits you
}

\section{Recommended Citation}

137. Monteagudo J, Cavarocchi N, ,Hehn B, Hasan N, Hirose H. Venoarterial extracorporeal membrane oxygenation (ECMO) for support during whole lung lavage for pulmonary alveolar proteinosis. Presented at Chest 2012, Atlanta GA, October 20-25.

This Article is brought to you for free and open access by the Jefferson Digital Commons. The Jefferson Digital Commons is a service of Thomas Jefferson University's Center for Teaching and Learning (CTL). The Commons is a showcase for Jefferson books and journals, peer-reviewed scholarly publications, unique historical collections from the University archives, and teaching tools. The Jefferson Digital Commons allows researchers and interested readers anywhere in the world to learn about and keep up to date with Jefferson scholarship. This article has been accepted for inclusion in Department of Surgery Faculty Papers by an authorized administrator of the Jefferson Digital Commons. For more information, please contact: JeffersonDigitalCommons@jefferson.edu. 


\section{Jefferson. Venoarterial extracorporeal membrane oxygenation (ECMO) for support during whole lung lavage for pulmonary alveolar proteinosis.}

Julie Monteagudo, MD'; Nicholas Cavarocchi, MD1; Boyd Hehn, MD²; Naveed Hasan,MD²; Hitoshi Hirose, MD, PhD'

${ }^{1}$ Department of Surgery, Thomas Jefferson University Hospital; ${ }^{2}$ Department of Pulmonary/Critical Care Medicine, Thomas Jefferson University

\section{Background}

- Whole lung lavage is the standard treatment for progressive PAP leading to respiratory compromise

'Venovenous support has been described in the literature, venoarterial support is only used rarely

\section{Objective}

We describe a case of pulmonary alveolar proteinosis (PAP) treated with whole lung lavage (WLL) using venoarterial ECMO for cardiopulmonary support rather than the conventional venovenous support and describe why this method was advantageous.

\section{Case Presentation}

-44 year old female with Bechet's disease, BMI 37 -Presents with progressive dyspnea, undergoes CT scan, suspicious for PAP

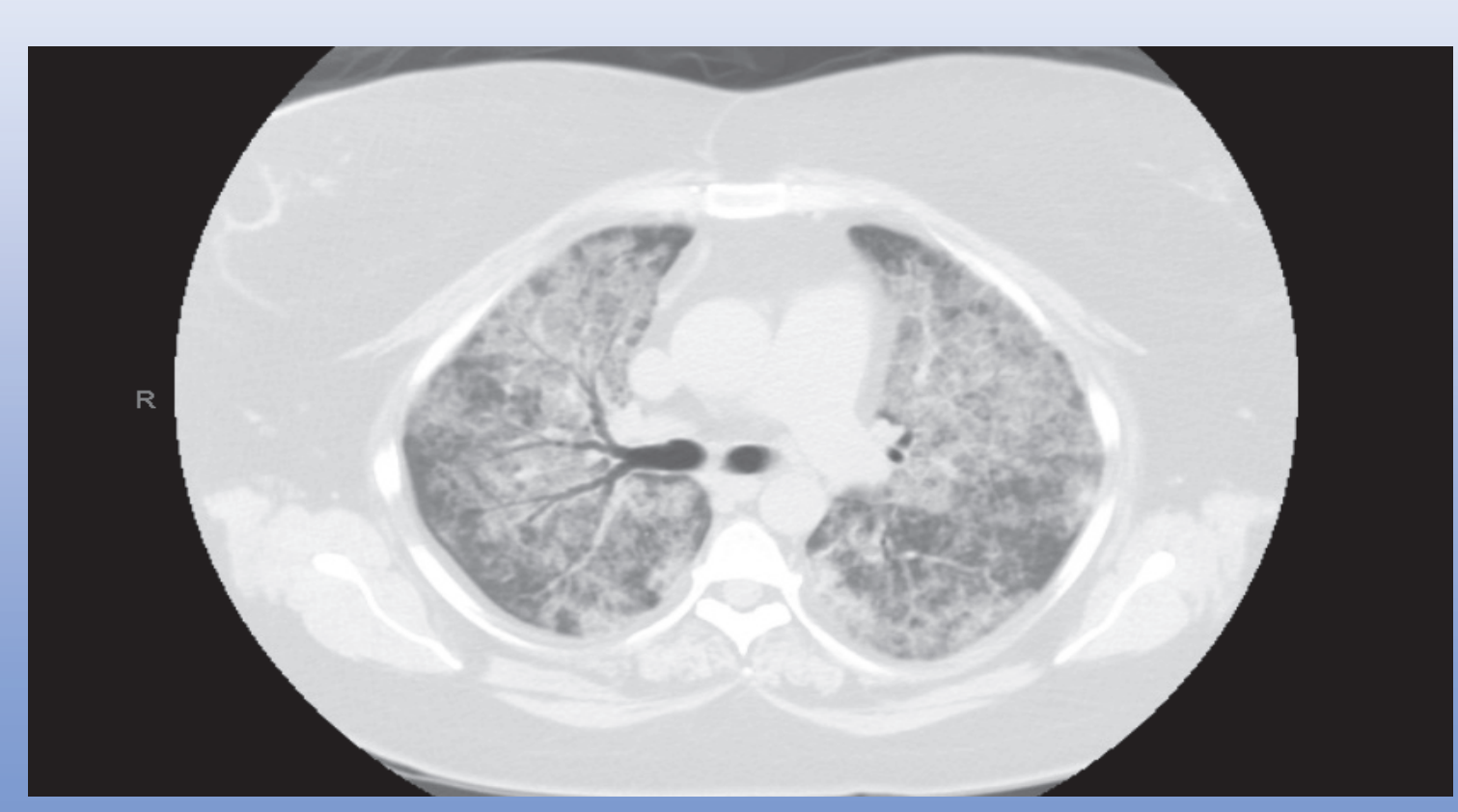

\section{Case Presentation}

-Respiratory compromise prompts VATS biopsy for definitive diagnosis, PAP found on biopsy

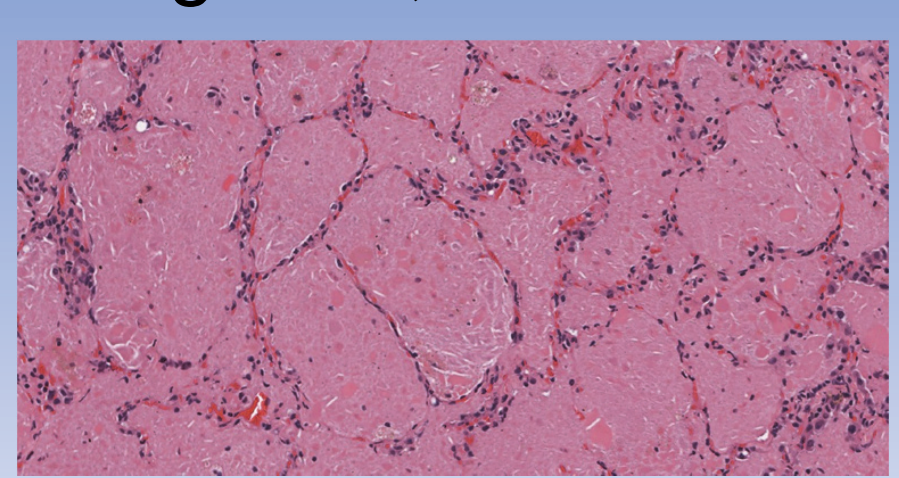

- Pt required intubation, difficult to oxygenate, taken to operating room emergently for VA ECMO and WLL

\section{Operative Details}

-Right femoral cannulation with 20F venous cannula and $18 \mathrm{~F}$ arterial cannula

-Retrograde arterial cannula used to preserve distal limb perfusion

-ECMO flows obtained were satisfactory at $4 \mathrm{~L} / \mathrm{min}$ -WLL subsequently performed using 12 liters in one liter instillations with chest physiotherapy between liters

-Appearance of fluid initially serosanguineous and turbid and ultimately became serous and transparent

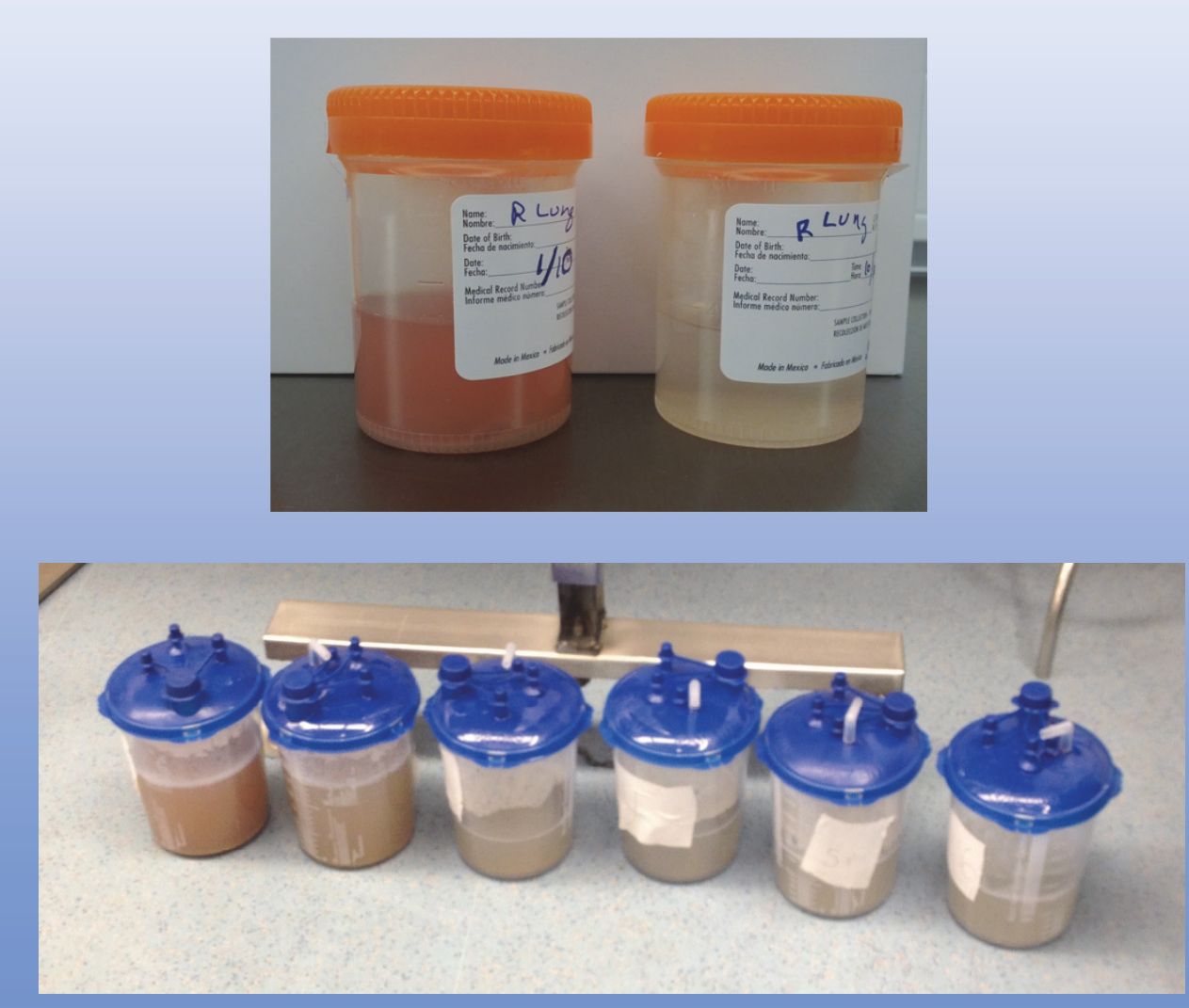

\section{Post Operative Course} -Decannulated from ECMO on POD\#5 with dramatic improvement in oxygenation -PAP thought to be secondary to Bechet's disease, no anti- GM CSF antibodies to allow treatment with Sargramostim

-Pt discharged from the hospital doing well in follow up

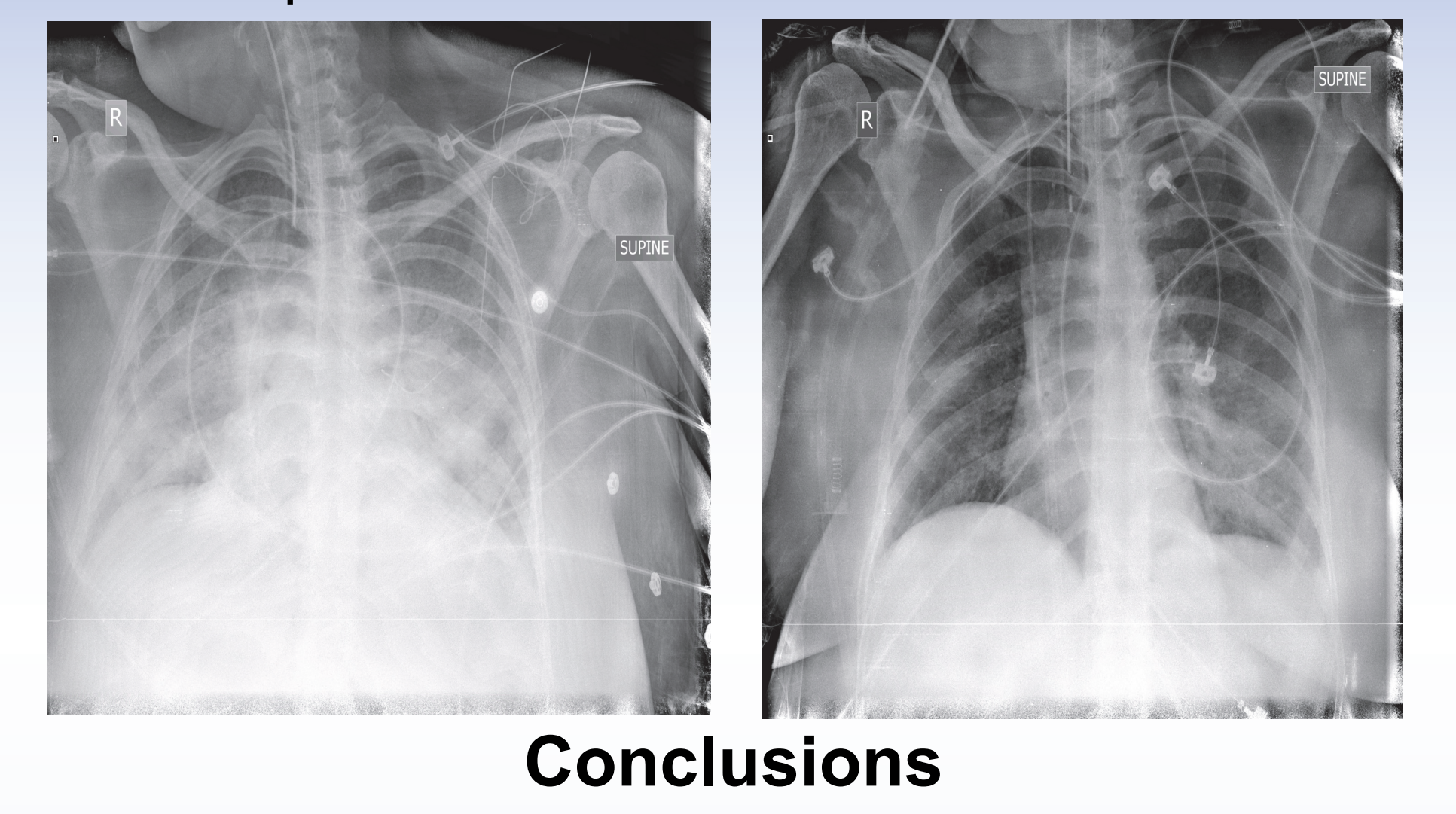

- We propose that VA ECMO is superior to VV ECMO during whole lung lavage for the following reasons:

-Hemodynamic support removes the strain on the right ventricle during the stress of WLL

- Avoids hypoxemia during WLL and post operatively

Allows safety during repositioning of patient during WLL to allow percussion and patient turns -Allows for bilateral lavage rather than staggered unilateral lavage

-VA ECMO allows hemodynamic and pulmonary support during WLL for PAP 